\title{
Serum Bone Markers and Coronary Artery Calcification in End Stage Renal Failure Patients and Kidney Transplant Recipients
}

Tanja Celic ${ }^{1 *}$, Josip Spanjol ${ }^{2}$, Antun Grskovic ${ }^{2}$, Melita Kukuljan ${ }^{3}$, Sanjin Racki ${ }^{4}$, Tomislav Kurelac ${ }^{1}$, Ivana Marić1 and Dragica Bobinac ${ }^{1}$

${ }^{1}$ Department of Anatomy, University Hospital Rijeka, Rijeka, Croatia

${ }^{2}$ Department of Urology, University Hospital Rijeka, Rijeka, Croatia

${ }^{3}$ Department of Radiology, University Hospital Rijeka, Rijeka, Croatia

${ }^{4}$ Department of Nephrology, University Hospital Rijeka, Rijeka, Croatia

\begin{abstract}
Background: Variety of growth factors and cytokines are involved in the process of bone turnover. Evidences are showing that alterations in OPG/RANK/RANKL system form the basis of many metabolic diseases. So, we evaluated the relationship between OPG and RANKL levels, to establish a possible relationship with other bone markers and coronary artery calcification.
\end{abstract}

Methods: Patients with chronic kidney disease and patients during the first year after transplantation had coronary artery scan and their blood was analyzed for serum bone markers. The following serum markers were measured: OPG, RANKL, BAP, TRAP5b and iPTH.

Results: All measured bone markers values increased with the disease progression and return to normal values during the first year after transplantation. Serum values of OPG, BAP, TRAP5b and iPTH are influenced by gender, age and dialysis duration. There is a significant negative correlation between PTH and OPG, and positive between PTH, BAP and TRAP5b values. No correlation between OPG and SRANKL, or OPG/sRANKL levels with other tested markers was found. In multivariate analysis of CACS revealed that OPG is significantly correlated with calcification in entire study population.

Conclusions: This study shows that increased bone turnover markers are present in chronic kidney disease but mainly depending on gender, age and dialysis duration. The effects of those factors are overridden by glucocorticoids effect in transplanted patients. The correlation of OPG with arterial calcification presents it as a possible calcification marker.

This is the first study on bone metabolism that covered Chronic Kidney Disease (CKD) patients, both predialysed and hemodialysed, as well as kidney transplant recipients. Results of our study demonstrate that serum levels of all investigated bone markers as well as calcification of coronary arteries are increased during CKD, with highest measured values in HD population.

Keywords: Bone turnover markers; Renal osteodistrophy; Metabolic bone disease; RANKL; OPG

\section{Introduction}

Kidney influences bone metabolism through maintaining calcium and phosphate balance, and enabling conversion of 25(OH)D3 into calcitriol. Impaired kidney function leads to severe change of bone mineralization and structure recognized as Renal Osteodistrophy (ROD) [1]. ROD occurs early during the course of chronic kidney disease and leads to increased bone fracture rate, morbidity and mortality [2]. Several forms of ROD are described in bone histology, ranging from high turnover bone disease accompanied with secondary hyperparathyroidism, to adynamic bone disease and osteomalacia with low bone turnover [3]. The prevalence of ROD subtypes depends on disease progression and differs in predialysed, dialysed and transplanted patients [4-6].

Besides histomorphometry, Parathyroid Hormone (PTH) is one of the major determinants of bone turnover $[7,8]$. PTH acts by binding to its receptor in target organs, mainly bone and kidney. Its role is to maintain adequate levels of plasma calcium by increasing synthesis of calcitriol, inducing osteoclast differentiation and bone resorption. In renal failure increased PTH acts as systemic toxin and is pathogenetic factor of many uremic complications. High PTH levels are related with high turnover bone disease, while low PTH levels relate to adynamic bone disease or osteomalacia. However, many manifestations of ROD cannot be explained exclusively by PTH excess or defect [9].
Bone metabolism disorder that develops during chronic renal failure often continues after kidney transplantation, partially owing its persistence to immunosuppressive therapy [10]. Pretransplant secondary hyperparathyroidism impacts initial posttransplant period and causes increased bone turnover in kidney transplant recipients $[11,12]$. In the majority of cases hyperparathyroidism improves 6 months to several years after transplantation, although it is observed that $25 \%$ of patients have persistently elevated PTH one year after transplantation $[13,14]$. Osteoporosis has emerged as serious clinical problem in patients with transplanted kidney [15]. To commence suitable therapeutic strategies for bone disease it is essential to understand histologic bone abnormalities and their development within time.

Studies show that combination of iPTH with biochemical markers

*Corresponding author: Tanja Celic, Department of Anatomy, Faculty of Medicine, Brace Branchetta 20, 51000 Rijeka, Croatia, Tel: +385 51651 143; Fax +385 51651 143; E-mail: tanja.celic@medri.hr

Received November 03, 2011; Accepted July 25, 2012; Published July 28, 2012

Citation: Celic T, Spanjol J, Grskovic A, Kukuljan M, Racki S, et al. (2012) Serum Bone Markers and Coronary Artery Calcification in End Stage Rena Failure Patients and Kidney Transplant Recipients. J Nephrol Therapeut 2:125 doi:10.4172/2161-0959.1000125

Copyright: (c) 2012 Celic T, et al. This is an open-access article distributed under the terms of the Creative Commons Attribution License, which permits unrestricted use, distribution, and reproduction in any medium, provided the original author and source are credited. 
that represent osteobalstic and osteoclastic activity will increase sensitivity and specificity to diagnose and monitor high, normal and low bone turnover. Recent years brought the discovery of new members of TNF receptor superfamily - OPG/RANK/RANKL system as regulators of bone remodeling. In bone tissue OPG is produced by osteoblasts and acts as decoy receptor that blocks interaction between RANK and its ligand RANKL. In this way reduces the number of active osteoclasts and increases bone volume and mineral density. RANKL is expressed on osteoblasts as transmembrane protein, but also can be found in circulation in soluble form [16]. Its actions stimulate osteoclasts differentiation and activation. Besides in bone, OPG and RANKL involvement in control of vascular and immune system is significant [17]. Cardiovascular disease is the leading cause of morbidity and mortality in chronic kidney disease patients and the growing evidence are linking interactions among mineral metabolism disorders and extraosseus calcifications [18-20]. It was shown that plasma osteoprotegerin is associated with mortality in hemodialysis patients [21].

Therefore we analyzed serum biochemical markers of bone metabolism and assessed their associations with vascular calcification during chronic kidney disease, in predialysed (CKD III and IV) and haemodialysed (CKDV) subjects. The same markers have been measured after kidney transplantation to detect possible changes during reestablishment of kidney-bone axis. We intended, as well, to examine influence of inevitable characteristics, such as gender, age and dialysis duration, on bone marker values.

\section{Subjects and Methods}

\section{Patients and baseline data}

A total of 160 patients from Clinical Hospital Rijeka, Croatia were included in this study. Patients were separated according to renal function into predialysed, hemodialysed and renal recipient group. In predialysed group 40 subjects ( 20 men, 20 women, median age 72 years (range 40-82)) were enrolled with chronic kidney insufficiency stages III or IV. This group included 17 chronic glomerulonephritis, 8 chronic interstitial nephritis, 6 polycystic disease, 4 diabetic nephropathy and 4 suffered from other diseases. In Hemodialysed (HD) group 90 subjects ( 45 men, 45 women, median age 64 years (range 38-89)) were enrolled. This group included 42 chronic glomerulonephritis, 21 chronic interstitial nephritis, 10 polycystic disease, 8 diabetic nephropathy and 9 suffered from other diseases.
Kidney allograft recipients were enrolled at the moment of transplantation and followed up 6 and 12 months post transplantation. In further text those groups will be referred to as Tx0, Tx6 and Tx12 group. These groups included 30 subjects (14 men, 16 women, median age 49 (28-67)). Prior the transplantation surgery Tx0 group patients were treated with hemodialysis, but were excluded from HD group. The reasons for excluding them from HD group were differences in dialysis duration, age and iPTH levels. All the patients in HD and Tx0 groups received regular hemodialysis three times a week with total duration of $12 \mathrm{~h}$. The mean duration of dialysis treatment was 69 and 94 months in the HD and Tx0 groups, respectively. They received either high flux polysulfone HD or on-line hemodiafiltration treatments with bicarbonate buffered dialysate. All the dialyzed patients were receiving concomitant drugs as calcium carbonate $(500 \mathrm{mg}$ to $3 \mathrm{~g} /$ day) and calcitriol $(0.25 \mu \mathrm{g})$. Patients in Tx6 and Tx12 groups had stable graft function (serum creatinine $1.5 \pm 0.3 \mathrm{mg} / \mathrm{dl}$ ). The immunosuppressive therapy included prednisone, mycophenolate mofetil and tacrolimus.

A control group of 40 healthy individuals matched for sex and age was studied at the same time. Inclusion criteria for this group were no bone and renal diseases, no therapy with medications that affect normal bone formation and normal PTH levels (Table 1).

\section{Laboratory measurements}

Venous blood was drawn in the morning after overnight fast. In transplantation group blood samples were collected three times as follows, immediately prior to kidney transplantation surgery (Tx0), 6 and 12 months after transplantation (Tx6, Tx12). The samples were centrifuged and sera aliquoted and stored at $-80^{\circ} \mathrm{C}$. No repeated thawing and freezing cycles occurred.

Measurements of creatinine, total calcium, ionized calcium, phosphate and albumin were provided at Clinical Hospital Rijeka by using standard autoanalyzer (Olympus Apparatus, Rungis, France). Intact PTH (iPTH) was measured using IMMULITE/IMMULITE 1000 Intact PTH (Siemens Medical Solution Diagnostics, Deerfield, USA). Levels of Bone Specific Alkaline Phosphatase (BAP) and TRAP5b were estimated with immunoassay from MetraBAP (Metra Biosystems, Mountain View, CA, USA). Serum OPG and sRANKL were measured using commercially available kit from Biomedica (Biomedica Gruppe, Wien, Austria).

\begin{tabular}{|c|c|c|c|c|c|}
\hline Patients characteristics & Predialysed $(\mathrm{N}=40)$ & $\mathrm{HD}(\mathrm{N}=90)$ & \multicolumn{3}{|c|}{$\mathrm{Tx} 0, \mathrm{Tx} 6, \mathrm{Tx} 12(\mathrm{~N}=30)$} \\
\hline $\begin{array}{l}\text { CaxPO4 }\left(\mathrm{mmol}^{2} / \mathrm{I}^{2}\right) \\
\text { total alkaline } \\
\text { phosphatase }(\mathrm{IU} / \mathrm{ml})\end{array}$ & $\begin{array}{c}5.66 \pm 1.82 \\
83.74 \\
(37.88-122.71)\end{array}$ & $\begin{array}{c}4.38 \pm 1.32 \\
97.94 \\
(49.09-492.11)\end{array}$ & $\begin{array}{c}4.83 \pm 1.20 \\
99.27 \\
(39.20-412.48)\end{array}$ & $\begin{array}{c}4.60 \pm 1.19 \\
60.83 \\
(41.76-103.01)\end{array}$ & $\begin{array}{c}4.82 \pm 1.67 \\
49.54 \\
(29.32-87.07)\end{array}$ \\
\hline albumin (g/dl) & $3.57 \pm 0.74$ & $3.67 \pm 0.32$ & $3.44 \pm 0.82$ & $3.29 \pm 0.49$ & $3.41 \pm 0.45$ \\
\hline HDL cholesterol (mmol/l) & $1.09 \pm 0.21$ & $1.43 \pm 0.14$ & $1.18 \pm 0.28$ & $1.23 \pm 0.14$ & $1.09 \pm 0.09$ \\
\hline LDL cholesterol (mmol/l) & $3.14 \pm 0.92$ & $3.97 \pm 1.03$ & $3.79 \pm 1.42$ & $3.48 \pm 0.79$ & $3.77 \pm 1.11$ \\
\hline BAP (U/I) & $\begin{array}{c}22.54 \\
(10.97-55.96)\end{array}$ & $\begin{array}{c}22.80 \\
(9.59-103.04)\end{array}$ & $\begin{array}{c}12.05 \\
(4.79-35.08)\end{array}$ & $\begin{array}{c}31.37 \\
(9.22-50.6)\end{array}$ & $\begin{array}{c}23.99 \\
(15.52-78.02)\end{array}$ \\
\hline TRAP5b (U/I) & $\begin{array}{c}3.80 \\
(0.84-8.30)\end{array}$ & $\begin{array}{c}4.16 \\
(0.87-14.51)\end{array}$ & $\begin{array}{c}3.66 \\
(1.40-9.02)\end{array}$ & $\begin{array}{c}3.24 \\
(1.91-10.53)\end{array}$ & $\begin{array}{c}3.88 \\
(1.86-8.75)\end{array}$ \\
\hline OPG (pmol/l) & $\begin{array}{c}11.44 \\
(3.5-26.66)\end{array}$ & $\begin{array}{c}13.88 \\
(4.33-26.68)\end{array}$ & $\begin{array}{c}7.29 \\
(3.79-11.65)\end{array}$ & $\begin{array}{c}5.04 \\
(3.48-14.20)\end{array}$ & $\begin{array}{c}5.22 \\
(2.87-14.26)\end{array}$ \\
\hline sRANKL (pmol/l) & $\begin{array}{c}1.10 \\
(0.28-4.42)\end{array}$ & $\begin{array}{c}2.83^{*} \\
(0.14-6.85)\end{array}$ & $\begin{array}{c}2.12 \\
(0.21-5.58)\end{array}$ & $\begin{array}{c}1.15 \\
(0.39-7.60)\end{array}$ & $\begin{array}{c}0.35 \\
(0.11-3.22)\end{array}$ \\
\hline iPTH (pmol/l) & $\begin{array}{c}22.38 \\
(2.97-66.22)\end{array}$ & $\begin{array}{c}33.85^{*} \\
(8.24-263.41)\end{array}$ & $\begin{array}{c}127.42^{*} \\
(28.72-140.00)\end{array}$ & $\begin{array}{c}14.11 \\
(2.11-47.54)\end{array}$ & $\begin{array}{c}11.96 \\
(2.39-49.6)\end{array}$ \\
\hline
\end{tabular}

Values are presented as median and range, or as average \pm S.E.M. ${ }^{*} P<0.05$ comparison between all group

Table 1: Biochemical parameters and bone marker values according to the groups of our patients. 
Citation: Celic T, Spanjol J, Grskovic A, Kukuljan M, Racki S, et al. (2012) Serum Bone Markers and Coronary Artery Calcification in End Stage Renal Failure Patients and Kidney Transplant Recipients. J Nephrol Therapeut 2:125. doi:10.4172/2161-0959.1000125

Page 3 of 7

\begin{tabular}{|c|c|c|c|c|c|c|c|c|c|c|}
\hline & \multicolumn{2}{|c|}{ BAP(U/I) } & \multicolumn{2}{|c|}{ TRAP5b(U/I) } & \multicolumn{2}{|c|}{ OPG(pmol/l) } & \multicolumn{2}{|c|}{ sRANKL(pmol/l) } & \multicolumn{2}{|c|}{ iPTH(pmol/l) } \\
\hline & male & female & male & female & male & female & male & female & male & female \\
\hline Control & 15.07 & 12.06 & 2.03 & 1.81 & 4.89 & 4.58 & 0.44 & 0.30 & 7.32 & 8.48 \\
\hline Predialysed & 17,67 & $25,71^{*}$ & 3,01 & $4,80^{*}$ & 11,50 & 12,64 & 1,58 & 0,28 & 25,10 & 15,40 \\
\hline HD & 17,98 & $32,85^{*}$ & 3,12 & $5,69^{*}$ & 15,98 & 12,28 & 2,60 & 3,06 & 31,90 & 34,10 \\
\hline
\end{tabular}

Values are presented as median and separated according to gender. ${ }^{*} P<0.05$

Table 2: Markers of bone metabolism in predialyzed, hemodialyzed patients (HD), and healthy volunteers (control).

\section{Imaging procedure}

From each studied group 20 subjects underwent a multi-row spiral CT (MSCT) to assess calcifications in coronary arteries. The Agatston scale [22] was used to interpret the results by Coronary Artery Calcification Score (CACS) expressed in Hounsfield Units (HU).

\section{Statistical analysis}

Subjects were classified in to two coronary calcification groups; mild to moderate $(\mathrm{CACS}<400 \mathrm{HU})$ and severe to very severe calcification (CACS $>400 \mathrm{HU}$ ) group. This classification is a modification of the one proposed by Rumberger et al. [23] who recommended dividing coronary artery calcification scores into four categories. For this study the distribution was based on the results of Raggi et al. [24] and Krasniak et al. [25]

To investigate age influence on bone marker values we divided subjects to those younger and older than 65 years, based on previous findings [26]. Duration of dialysis was divided into three time groups $(<36,36-72$ and $>72$ months) and bone marker values in those groups were examined.

All data are presented as mean, SD, median and range. Statistical methods included Mann-Whitney $U$ test for unpaired data, ANOVA for nonparametric data and Spearman's correlation coefficient. Data were analyzed using Statistica 6.0.computer software. A $P$ value less than 0.05 was considered as statistically significant.

\section{Results}

\section{Bone marker values in studied groups}

Baseline biochemical parameters and bone marker values of studied groups are outlined in table 1. Results show increase in bone marker values with progression of chronic kidney disease. In predialysed and HD group all measured markers are significantly higher when compared to control. Predialysed and HD group have similar serum concentrations of BAP, TRAP5b and OPG, while significantly higher values of sRANKL and iPTH are obtained in HD group $(P=0.004$; 0.008). Subjects in HD group have significantly higher values of sRANKL $(P=0.022)$ when compared to other groups.

During first year after transplantation OPG and sRANKL serum concentrations normalize and obtain values measured in controls. Six months after transplantation iPTH levels are significantly declined and same as those in control group. Unlike, in posttransplant period (Tx6 and Tx12) BAP and TRAP5b remain elevated or even increased when compared to Tx0 group. Between BAP and TRAP5b values positive correlation was observed. Those two markers correlated positively in HD $(\mathrm{r}=0.673 ; P<0.001)$, in Tx0 $(\mathrm{r}=0.746 ; P=0.008)$ and in Tx12 group $(\mathrm{r}=0.548, P=0.012)$. No correlations between OPG and sRANKL were found in any studied group.

\section{Influence of gender, age and dialysis duration on bone marker} values

In overall studied population gender didn't correlate with any bone marker. When separated from controls and transplantation group, females in predialysed and HD group presented significantly higher BAP $(P=0.050)$ and TRAP5b $(P \leq 0.001)$ serum levels, whereas OPG, sRANKL and iPTH were not gender influenced (Table 2). In transplantation groups studied markers were not gender influenced.

In the study subjects OPG positively correlated with age $(\mathrm{r}=0.507$; $P<0.001)$, while iPTH negatively correlated with age $(\mathrm{r}=-0.266$; $P=0.005$ ) (Figures 1 and 2). After adjusting age data (as described in statistical analysis) TRAP5b had significantly increased values in HD patients older than 65 years $(P=0.025)$. No age influence on sRANKL, iPTH and BAP levels pre or post transplantation was observed.

Dialysis duration positively correlated with iPTH ( $r=0.321$, $P=0.007)$. When dialysis duration was distributed into three time groups, BAP, TRAP5b and OPG values were significantly increased $(P=0.036 ; 0.048 ; 0.022)$ in subjects dialyzed for over 72 months. sRANKL showed no dependance on dialysis duration (Table 3).

\section{Correlations between iPTH and bone markers; iPTH levels in studied groups}

iPTH positively correlated with BAP and TRAP5b values $(\mathrm{r}=0.346$, $P<0.001 ; \mathrm{r}=0.263, P=0.026$ ) (Figures 3 and 4 ) and negatively with OPG $(\mathrm{r}=-0.382 ; P=0.003)$. We did not find any correlation between sRANKL or the sRANKL/OPG ratio and iPTH levels in overall studied population, or when separating data by groups.

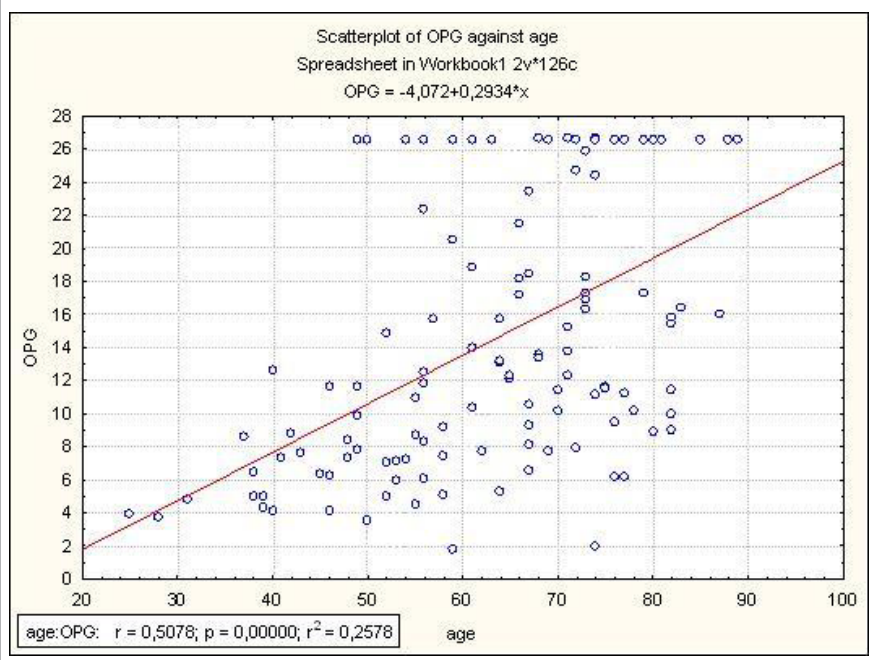

Figure 1: Correlation analysis result between OPG serum values and age in entire study population (Spearman`s r-coefficient). 
Citation: Celic T, Spanjol J, Grskovic A, Kukuljan M, Racki S, et al. (2012) Serum Bone Markers and Coronary Artery Calcification in End Stage Renal Failure Patients and Kidney Transplant Recipients. J Nephrol Therapeut 2:125. doi:10.4172/2161-0959.1000125

Page 4 of 7

We stratified patients in all studied groups according to plasma iPTH in lower, middle and upper tertile $(<11,11-33,>33 \mathrm{pmol} / \mathrm{l})$. In pre-dialysis group $40 \%$ of subjects were within upper, $42 \%$ in middle and $18 \%$ in lower iPTH tertile. Similar distribution towards iPTH in HD patients was found, with $16 \%$ in lower, $40 \%$ in middle and $44 \%$ in upper tertile. In Tx0 group 53\% of subjects had iPTH higher than $33 \mathrm{pmol} / \mathrm{l}$, and $47 \%$ were within middle iPTH tertile. In Tx6 and Tx12 group $80 \%$ of subjects had iPTH in middle tertile, and $20 \%$ had iPTH lower than $11 \mathrm{pmol} / \mathrm{l}$. Bone marker values according to iPTH are shown in table 4.

\section{Coronary artery calcification}

Coronary artery calcifications were observed in $86 \%$ of the patients, with CACS ranging from $0-7338 \mathrm{HU}$ (424 median). ANOVA revealed significantly increased CACS values in HD group $(P<0.001)$ (Table 5$)$. In univariate analysis CACS positively correlated with OPG and BAP in entire studied population. No correlation was found with other tested parameters (Table 6). In multivariate analysis between CACS and before mentioned parameters only OPG remained independent predictor of CACS $(\mathrm{r}=0.311, P=0.028)$.

After adjusting CACS at cut off value of $400 \mathrm{HU}$ (described in statistical analysis) values of BAP, TRAP5b, OPG and iPTH were significantly increased in severe calcification group (Table 7).

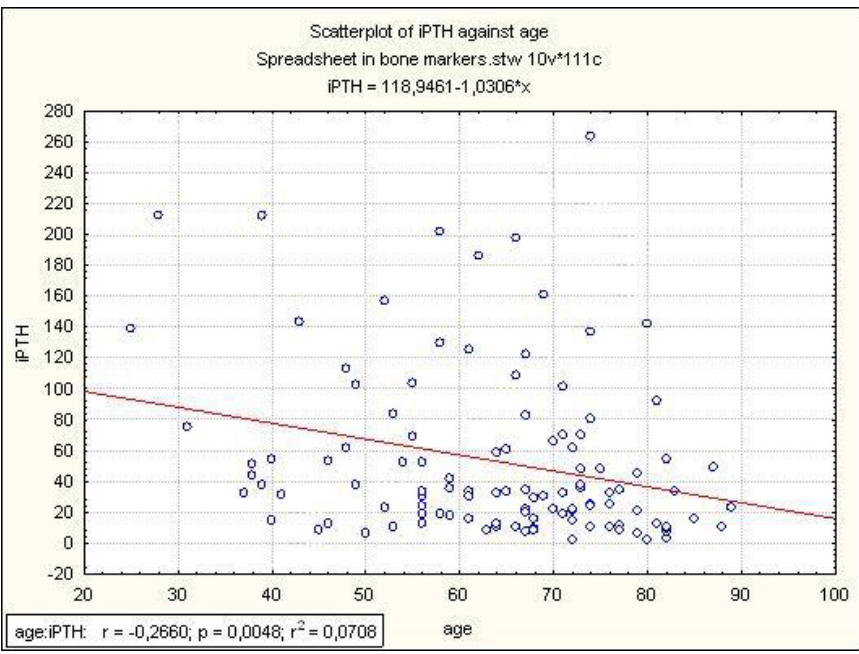

Figure 2: Correlation analysis result between iPTH serum values and age in entire study population (Spearman`s r-coefficient).

\begin{tabular}{|l|c|c|c|}
\hline \multirow{2}{*}{} & \multicolumn{3}{|c|}{ Dialysis duration (months) } \\
\cline { 2 - 4 } & $<36$ & $\mathbf{3 6 - 7 2}$ & $>72$ \\
\hline $\begin{array}{l}\text { Patients } \\
\text { number } \\
\text { (percentage) }\end{array}$ & $35 / 120(29 \%)$ & $41 / 120(34 \%)$ & $44 / 120(37 \%)$ \\
\hline BAP (U/I) & $18.51(5.80-37.66)$ & $24.80(9.78-89.12)$ & $32.65^{*}(11.49-130.04)$ \\
\hline TRAP5b (U/I) & $2.90(0.82-8.23)$ & $4.08(1.81-9.91)$ & $5.26^{*}(2.65-14.50)$ \\
\hline OPG (pmol/I) & $11.57(4.30-26.67)$ & $11.60(6.48-26.67)$ & $16.38^{*}(4.51-26.67)$ \\
\hline $\begin{array}{l}\text { sRANKL } \\
\text { (pmol/I) }\end{array}$ & $2.56(0.89-3.80)$ & $2.51(0.14-6.85)$ & $2.85(0.41-6.28)$ \\
\hline iPTH (pmol/l) & $23.20(8.50-61.30)$ & $31.70(7.50-$ & $68.40^{*}(11.30-263.00)$ \\
\hline
\end{tabular}

All values are expressed as median (range). ${ }^{*} P<0.05$

Table 3: Bone marker values according to dialysis duration.

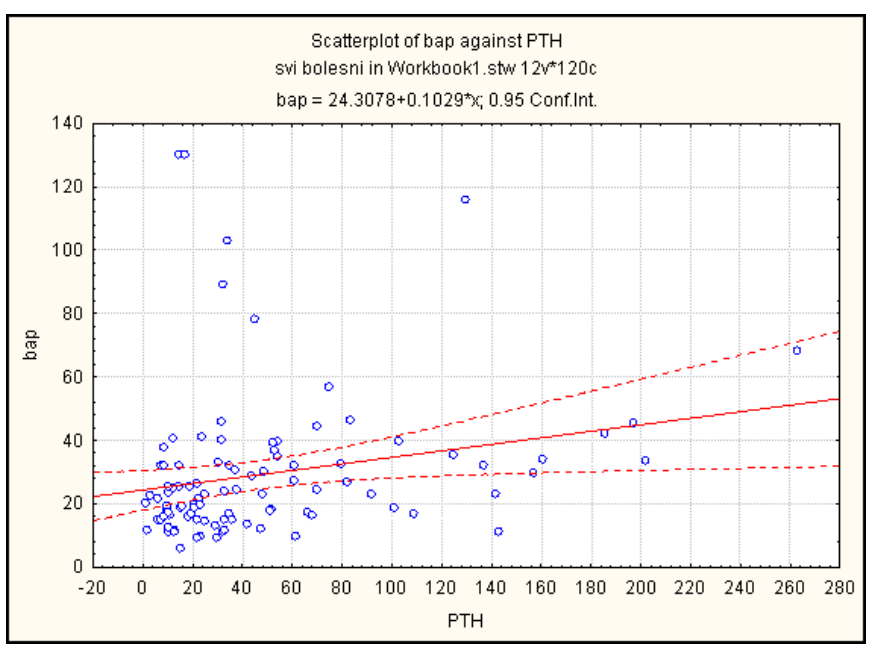

Figure 3: Correlation analysis results between iPTH and BAP, TRAP5b serum values in entire study population (Spearman`s r-coefficient).

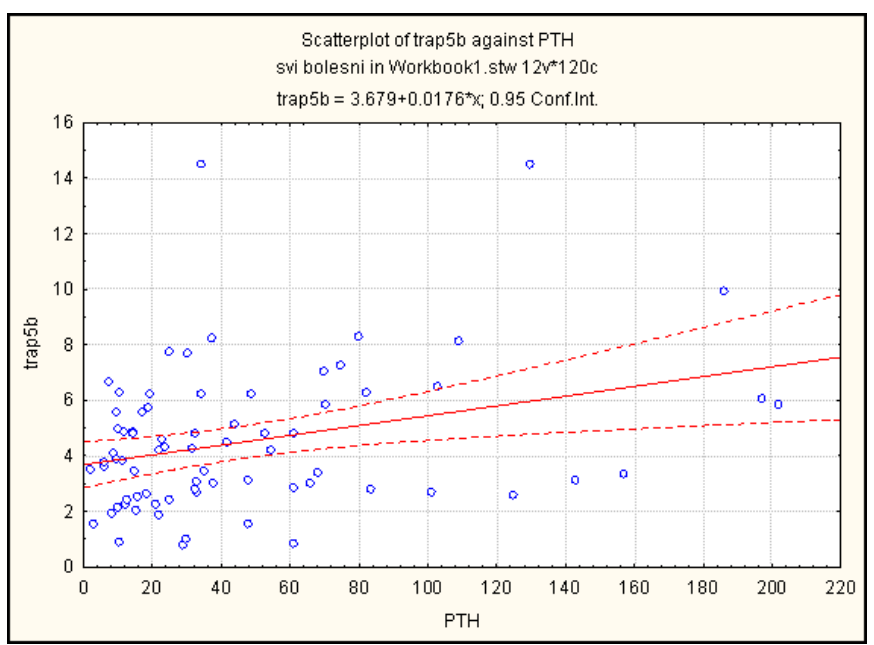

Figure 4: Correlation analysis results betweeen iPTH and BAP, TRAP5b serum values in entire study population (Spearman`s r-coefficient).

\begin{tabular}{|l|c|c|c|}
\hline & $\begin{array}{c}\text { iPTH } \\
<11 \mathbf{~ p m o l / l}\end{array}$ & $\begin{array}{c}\text { iPTH } \\
\mathbf{1 1 - 3 3} \mathbf{~ p m o l / I}\end{array}$ & $\begin{array}{c}\text { iPTH } \\
\mathbf{3} 3 \mathbf{~ p m o l} / \mathbf{l}\end{array}$ \\
\hline Percentage & $18 \%$ & $45 \%$ & $27 \%$ \\
\hline BAP (U/I) & $16.87(9.78-32.10)$ & $21.34(9.42-67.18)$ & $31.83^{*}(9.59-130.24)$ \\
\hline TRAP5b (U/I) & $3.47(1.94-5.05)$ & $4.27(1.78-7.12)$ & $5.56^{*}(0.9-9.9)$ \\
\hline OPG (pmol/I) & $14.41(6.03-26.57)$ & $13.05(4.83-26.57)$ & $13.03(4.81-26.57)$ \\
\hline $\begin{array}{l}\text { sRANKL } \\
\text { (pmol/l) }\end{array}$ & $2.38(0.14-3.50)$ & $2.86(0.52-5.59)$ & $3.00(0.23-6.28)$ \\
\hline
\end{tabular}

All values are expressed as median (range). ${ }^{*} P<0.05$

Table 4: Bone marker values according to $\mathrm{iPTH}$ levels in entire study population.

\section{Discussion}

This is the first study on bone metabolism that covered Chronic Kidney Disease (CKD) patients, both predialysed and hemodialysed, as well as kidney transplant recipients. Data about comparison of mineral metabolism in afore mentioned groups are limited. Results of our study demonstrate that serum levels of all investigated bone markers as well 
as calcification of coronary arteries are increased during CKD, with highest measured values in HD population, which is in agreement with previous studies $[23,27,28]$.

One of the major findings in this research is that female gender of the patients is determinant factor for high BAP and TRAP5b levels in predialysed and HD group. Gender influence on elevated BAP levels was firstly described in postmenopausal osteoporotic women with normal renal function [29]. Completion of ovarian function increases bone turnover due to lack of the antiresorptive effect of estrogens. Later, authors reported increased BAP levels in females on peritoneal dialysis [30]. Our investigation confirmed this finding in predialysed and found the same result in HD population. Available data report no gender influence on TRAP5b [31,32]. Our results show that women in predialysed and HD group have statistically increased TRAP5b values. Even more, if this study was performed solely on male patients, BAP and TRAP5b values in predialysed and HD group would be the same as those obtained in healthy volunteers.

Previously BAP was presented as one of the valuable predictors of low and high bone turnover, especially in correlation with PTH [33]. Kidney Disease Outcomes Quality Initiative (KDQQI) guidelines state that high PTH levels are causative factor for increasing BAP levels and thus bone resorption. In our study $40 \%$ of patients in predialysed and $40 \%$ in HD group had iPTH values above 33pmol/l. High iPTH levels in these groups significantly correlated with BAP and TRAP5b values. However, when adjusted for gender, BAP and TRAP5b results, measured in male patients, did not correlate to iPTH values. Findings on serum TRAP5b have shown its significant correlation with osteoclast number, mineral apposition rate and estimation of the precise BMD

\begin{tabular}{|c|c|c|c|c|}
\hline & Control & Predialysed & Hemodialysed & Transplantation \\
\hline $\begin{array}{c}\text { CACS } \\
(H U)\end{array}$ & $89.21 \pm 32.18$ & $876.92 \pm 280.84$ & $2195.23 \pm 637.94^{*}$ & $215.60 \pm 60.40$ \\
\hline
\end{tabular}

All values are expressed as average \pm S.E.M. ${ }^{*} P<0.001$

Table 5: Coronary artery calcification score (CACS) in studied groups.

\begin{tabular}{|c|c|c|}
\hline Parameter & $\mathbf{R}$ & $\boldsymbol{P}$ value \\
\hline Age & 0.228 & 0.175 \\
\hline Dialysis duration & 0.235 & 0.256 \\
\hline iPTH (pmol/l) & 0.251 & 0.192 \\
\hline TRAP5b (U/l) & 0.162 & 0.384 \\
\hline BAP (U/l) & $\mathbf{0 . 4 5 4}$ & $\mathbf{0 . 0 0 8}$ \\
\hline OPG (pmol/l) & $\mathbf{0 . 4 6 7}$ & $\mathbf{0 . 0 1 1}$ \\
\hline sRANKL (pmol/l) & 0.082 & 0.657 \\
\hline CaxPO4 (mmol/l) & 0.080 & 0.681 \\
\hline
\end{tabular}

Table 6: Correlation analysis results between coronary artery calcification score (CACS) and selected parameters in entire study population (Spearman's r-coefficient).

\begin{tabular}{|l|c|c|c|}
\hline \multirow{2}{*}{ Parameter } & \multicolumn{2}{|c|}{ ca score } & \multirow{2}{*}{$\boldsymbol{P}$ value } \\
\cline { 2 - 3 } & $<\mathbf{4 0 0}$ & $\mathbf{> 4 0 0}$ & \\
\hline iPTH (pmol/l) & $27.08 \pm 5.23$ & $79.12 \pm 14.50$ & $\mathbf{0 . 0 0 9}$ \\
\hline TRAP5b (U/l) & $2.80 \pm 0.38$ & $4.97 \pm 0.44$ & $\mathbf{0 . 0 0 2}$ \\
\hline BAP (U/l) & $18.18 \pm 1.43$ & $29.28 \pm 2.24$ & $\mathbf{0 . 0 0 2}$ \\
\hline OPG (pmol/l) & $5.81 \pm 0.33$ & $11.27 \pm 0.92$ & $<\mathbf{0 . 0 0 1}$ \\
\hline sRANKL (pmol/l) & $2.58 \pm 0.36$ & $2.21 \pm 0.32$ & 0.524 \\
\hline CaxPO4 (mmol/l) & $4.11 \pm 0.15$ & $4.90 \pm 0.25$ & $\mathbf{0 . 0 4 0}$ \\
\hline
\end{tabular}

All values are expressed as average \pm S.E.M.

Table 7: Values of studied parameters by coronary artery calcium score category. change in HD patients, also histomorphometry showed that TRAP5b is superior to iPTH as indicator of bone resorption [34]. In study of Malyszko et al. [30], TRAP5b correlated significantly with iPTH and BAP in kidney transplant recipients and dialyzed patients [30].

Is it likely that elevated PTH in predialysed and HD patients did not directly affect serum BAP and TRAP5b values. Or if it did, was the proportion of this influence minor in comparison to PTH serum values? Another question arises from obtained results, why are BAP and TRAP5b levels unchanged in male subjects when compared to control? Is the development of ROD happening in the same manner in both genders?

Most conflicting reports about circulating OPG and RANKL levels in CKD are published up to date. Some authors state that elevated OPG levels are inhibiting stimulation of osteoclastogenesis induced by PTH, causing peripheral resistance to PTH [35]. Others explain high OPG levels as compensatory mechanism that can prevent bone loss [36]. Both are supported by our results showing the negative correlation between OPG and iPTH values, also both markers correlated with age. The positive correlation between age and OPG was already noticed in healthy population and end stage renal disease [37,38]. As shown previously, increased age and high OPG values are associated with occurrence of cardiovascular diseases, which is one of the leading mortality causes in HD population. Results of Morena et al. [17] report OPG levels as independent prognostic factor for vascular damage [17]. Their results are in concordance with our findings that OPG is independent predictor of high CACS. Our results also show that OPG correlates with dialysis duration, which was noticed already $[39,40]$. Increased OPG level with longer dialysis duration may be related to hemodialysis procedure itself, since it has been reported that it is not removed through polysulfon hemodialysis membrane [41].

iPTH inhibits the synthesis of OPG and stimulates RANKL production in bone [42]. In the light of this evidence we compared values of OPG, RANKL and iPTH in different stages of renal insufficiency. Our results show that in HD group sRANKL and iPTH values were significantly higher from predialysed group, but there was no correlation between two markers. Previously, Luznik et al. [43] reported that $\mathrm{PTH}$ increases bone resorption through elevated serum RANKL levels [43]. Other authors found sRANKL concentrations to be higher, lower or within normal range in HD [44,45]. Also, it is noticed that sRANKL levels do not describe bone mineral density well [46].

Knowing the biological interference of OPG and sRANKL actions, it is surprising to find a lack of correlation between their serum values. This is also a common finding in several studies, suggesting the importance of different mechanisms besides iPTH that are involved in the regulation of their synthesis. Also, when interpreting serum measured values it is important to consider that variety of tissues are expressing OPG and sRANKL [47].

This study also evaluated 30 transplant recipients to determine bone marker alterations one year after transplantation. We had the rare opportunity to observe dynamic changes of serum values regarding bone metabolism in homogenized and time controlled survey. In our study overactivity of iPTH observed in pre transplantation period, normalizes during first six months after transplantation. Despite iPTH normalization, elevated biochemical bone markers indicate the ongoing high bone turnover and increased bone resorption. This characteristic of bone metabolism during first post transplantation year is reported 
in many studies, and is considered as the main cause of bone loss and reduced bone mineral density in renal recipients $[48,49]$.

In our and other studies BAP levels were increased in the first post transplantation year, in later period decreasing trend began $[49,50]$. Up to date there are no data on TRAP5b, OPG and sRANKL serum levels in first year after transplantation. In our study TRAP5b was elevated during first year after transplantation, and its levels correlated positively with serum BAP. Malysko et al. [30] reported about normal TRAP5b levels, but the patients enrolled in that study 1-10 years after transplantation [30]. Our results show that sRANKL and OPG values return to those measured in healthy volunteers at the end of the first year post transplantation. As written prior in this text, there is a possibility of falsely elevated OPG levels due to accumulation on hemodialysis, which can partially explain normalization of its levels in renal recipients.

In conclusion, our results are showing the importance of gender, age and dialysis duration in interpretation of bone marker values. Female gender and older age were major contributors to increased serum BAP and TRAP5b values in hemodialysed group. Whether BAP and TRAP5b elevation is directly connected with the increase of iPTH remains unclear and requires further investigation. If this study was conducted solely on male subjects there would be no increase in BAP and TRAP5b serum values compared to healthy volunteers. The present study also confirms age dependant serum OPG increase, which is likely caused with age dependant iPTH decrease and thus lost of OPG inhibition.

\section{References}

1. Moe SM, Drüeke T, Lameire N, Eknoyan G (2007) Chronic kidney diseasemineral-bone disorder: a new paradigm. Adv Chronic Kidney Dis 14: 3-12.

2. Martin KJ, Olgaard K, Coburn JW, Coen GM, Fukagawa M, et al. (2004) Diagnosis, assessment, and treatment of bone turnover abnormalities in renal osteodystrophy. Am J Kidney Dis 43: 558-565.

3. Schwarz C, Sulzbacher I, Oberbauer R (2006) Diagnosis of renal osteodystrophy. Eur J Clin Invest 36: 13-22.

4. Bervoets AR, Spasovski GB, Behets GJ, Dams G, Polenakovic MH, et al. (2003) Useful biochemical markers for diagnosing renal osteodystrophy in predialysis end-stage renal failure patients. Am J Kidney Dis 41: 997-1007.

5. Haas M, Leko-Mohr Z, Roschger P, Kletzmayr J, Schwarz C, et al. (2002) Osteoprotegerin and parathyroid hormone as markers of high-turnove osteodystrophy and decreased bone mineralization in hemodialysis patients. Am J Kidney Dis 39: 580-586.

6. Monier-Faugere MC, Mawad H, Qi Q, Friedler RM, Malluche HH (2000) High prevalence of low bone turnover and occurrence of osteomalacia after kidney transplantation. J Am Soc Nephrol 11: 1093-1099.

7. Ferreira MA (2000) Diagnosis of renal osteodystrophy: when and how to use biochemical markers and non-invasive methods; when bone biopsy is needed. Nephrol Dial Transplant 15: 8-14.

8. Qi Q, Monier-Faugere MC, Geng Z, Malluche HH (1995) Predictive value of serum parathyroid hormone levels for bone turnover in patients on chronic maintenance dialysis. Am J Kidney Dis 26: 622-631.

9. Solal ME, Sebert JL, Boudailliez B, Marie A, Moriniere P, et al. (1991) Comparison of intact, midregion, and carboxy terminal assays of parathyroid hormone for the diagnosis of bone disease in hemodialyzed patients. J Clin Endocrinol Metab 73: 516-524.

10. Dissanayake IR, Epstein S (1998) The fate of bone after renal transplantation. Curr Opin Nephrol Hypertens 7: 389-395.

11. Hruska KA, Teitelbaum SL (1995) Renal osteodystrophy. N Engl J Med 333 166-174.

12. Sherrard DJ, Hercz G, Pei Y, Maloney NA, Greenwood C, et al. (1993) The spectrum of bone disease in end-stage renal failure--an evolving disorder Kidney Int 43: 436-442.
13. Bonarek H, Merville P, Bonarek M, Moreau K, Morel D, et al. (1999) Reduced parathyroid functional mass after successful kidney transplantation. Kidney Int 56: 642-649.

14. Parfitt AM (1997) The hyperparathyroidism of chronic renal failure: a disorder of growth. Kidney Int 52: 3-9.

15. Lukert BP, Raisz LG (1990) Glucocorticoid-induced osteoporosis: pathogenesis and management. Ann Intern Med 112: 352-364.

16. Yasuda H, Shima N, Nakagawa N, Yamaguchi K, Kinosaki M, et al (1998) Osteoclast differentiation factor is a ligand for osteoprotegerin/ osteoclastogenesis-inhibitory factor and is identical to TRANCE/RANKL. Proc Natl Acad Sci U S A 95: 3597-3602.

17. Baud'huin M, Lamoureux F, Duplomb L, Rédini F, Heymann D (2007) RANKL, RANK, osteoprotegerin: key partners of osteoimmunology and vascular diseases. Cell Mol Life Sci 64: 2334-2350.

18. Foley RN, Parfrey PS, Sarnak MJ (1998) Clinical epidemiology of cardiovascular disease in chronic renal disease. Am J Kidney Dis 32: S112-S119.

19. Cheung AK, Sarnak MJ, Yan G, Dwyer JT, Heyka RJ, et al. (2000) Atherosclerotic cardiovascular disease risks in chronic hemodialysis patients. Kidney Int 58: 353-362.

20. Kato A, Takita T, Maruyama Y, Kumagai H, Hishida A (2003) Impact of carotid atherosclerosis on long-term mortality in chronic hemodialysis patients. Kidney Int 64: 1472-1479.

21. Morena M, Terrier N, Jaussent I, Leray-Moragues H, Chalabi L, et al. (2006 Plasma osteoprotegerin is associated with mortality in hemodialysis patients. $J$ Am Soc Nephrol 17: 262-270.

22. Agatston AS, Janowitz WR, Hildner FJ, Zusmer NR, Viamonte M Jr, et al. (1990) Quantification of coronary artery calcium using ultrafast computed tomography. J Am Coll Cardiol 15: 827-832.

23. Rumberger JA (2008) Coronary artery calcium scanning using computed tomography: clinical recommendations for cardiac risk assessment and treatment. Semin Ultrasound CT MR 29: 223-229.

24. Raggi P, Boulay A, Chasan-Taber S, Amin N, Dillon M, et al. (2002) Cardiac calcification in adult hemodialysis patients. A link between end-stage renal disease and cardiovascular disease? J Am Coll Cardiol 39: 695-701.

25. Stompor T, Rajzer M, Pasowicz M, Krasniak A, Sulowicz W, et al. (2006) Coronary artery calcification, common carotid artery intima-media thickness and aortic pulse wave velocity in patients on peritoneal dialysis. Int $\mathrm{J}$ Artif Organs 29: 736-744

26. Grzegorzewska AE, Mlot M (2006) Serum markers of bone turnover in dialyzed patients separated according to age. Int Urol Nephrol 38: 311-316.

27. Moe SM, O'Neill KD, Fineberg N, Persohn S, Ahmed S, et al. (2003) Assessment of vascular calcification in ESRD patients using spiral CT. Nephro Dial Transplant 18: 1152-1158.

28. Desai MP, Bhanuprakash KV, Khatkhatay MI, Donde UM (2007) Age-related changes in bone turnover markers and ovarian hormones in premenopausal and postmenopausal Indian women. J Clin Lab Anal 21: 55-60.

29. Couttenye MM, D'Haese PC, Deng JT, Van Hoof VO, Verpooten GA, et al (1997) High prevalence of adynamic bone disease diagnosed by biochemical markers in a wide sample of the European CAPD population. Nephrol Dial Transplant 12: 2144-2150.

30. Malyszko J, Malyszko JS, Pawlak K, Wolczynski S, Mysliwiec M (2006) Tartrate-resistant acid phosphatase $5 \mathrm{~b}$ and its correlations with other markers of bone metabolism in kidney transplant recipients and dialyzed patients. Adv Med Sci 51: 69-72.

31. Poege U, Gerhardt T, Klehr KU, Klingmueller D, Sauerbruch T (2002) Tartrateresistant acid phosphatase $5 \mathrm{~b}$ in bone metabolism in patients on peritoneal dialysis. J Amer Soc Nephrol 13:138-141.

32. Ueda M, Inaba M, Okuno S, Maeno Y, Ishimura E, et al. (2005) Serum $\mathrm{BAP}$ as the clinically useful marker for predicting BMD reduction in diabetic hemodialysis patients with low PTH. Life Sci 77: 1130-1139.

33. Chu P, Chao TY, Lin YF, Janckila AJ, Yam LT (2003) Correlation between histomorphometric parameters of bone resorption and serum type $5 \mathrm{~b}$ tartrateresistant acid phosphatase in uremic patients on maintenance hemodialysis Am J Kidney Dis 41: 1052-1059. 
Citation: Celic T, Spanjol J, Grskovic A, Kukuljan M, Racki S, et al. (2012) Serum Bone Markers and Coronary Artery Calcification in End Stage Renal Failure Patients and Kidney Transplant Recipients. J Nephrol Therapeut 2:125. doi:10.4172/2161-0959.1000125

Page 7 of 7

34. Huang JC, Sakata T, Pfleger LL, Bencsik M, Halloran BP, et al. (2004) PTH differentially regulates expression of RANKL and OPG. J Bone Miner Res 19: 235-244.

35. Hofbauer LC, Kühne CA, Viereck V (2004) The OPG/RANKL/RANK system in metabolic bone diseases. J Musculoskelet Neuronal Interact 4: 268-275.

36. Shidara K, Inaba M, Okuno S, Yamada S, Kumeda Y, et al. (2008) Serum levels of TRAP5b, a new bone resorption marker unaffected by renal dysfunction, as a useful marker of cortical bone loss in hemodialysis patients. Calcif Tissue Int 82: $278-287$

37. Kudlacek S, Schneider B, Woloszczuk W, Pietschmann P, Willvonseder R, et al. (2003) Serum levels of osteoprotegerin increase with age in a healthy adult population. Bone 32: 681-686

38. Khosla S, Arrighi HM, Melton LJ 3rd, Atkinson EJ, O'Fallon WM, et al. (2002) Correlates of osteoprotegerin levels in women and men. Osteoporos Int 13 394-399.

39. Nakashima A, Yorioka N, Doi S, Takasugi N, Shigemoto K, et al. (2006) Osteoprotegerin and bone mineral density in hemodialysis patients. Osteoporos Int 17: 841-846.

40. Wittersheim E, Mesquita M, Demulder A, Guns M, Louis O, et al (2006) OPG RANK-L, bone metabolism, and BMD in patients on peritoneal dialysis and hemodialysis. Clin Biochem 39: 617-622.

41. Kazama JJ, Kato H, Sato T, Shigematsu T, Fukagawa M, et al. (2002) Circulating osteoprotegerin is not removed through haemodialysis membrane. Nephrol Dial Transplant 17: 1860-1861.

42. Lee SK, Lorenzo JA (1999) Parathyroid hormone stimulates TRANCE and inhibits osteoprotegerin messenger ribonucleic acid expression in murine bone marrow cultures: correlation with osteoclast-like cell formation. Endocrinology 140: 3552-3561.

43. Avbersek-Luznik I, Balon BP, Rus I, Marc J (2005) Increased bone resorption in HD patients: is it caused by elevated RANKL synthesis? Nephrol Dial Transplant 20: 566-570.

44. Doumouchtsis K, Perrea D, Doumouchtsis S, Tziamalis M, Poulakou M, et al. (2009) Regulatory effect of parathyroid hormone on sRANKL-osteoprotegerin in hemodialysis patients with renal bone disease. Ther Apher Dial 13: 49-55

45. Wei T, Wang M, Wang M, Gan LY, Li X (2009) Relationship of sRANKL leve and vascular calcification score to cardiovascular events in maintenance hemodialysis patients. Blood Purif 28: 342-345.

46. Chiba Y, Onouchi T, Ikeda T, Adachi J, Tamura Y, et al. (2009) Implications of measuring soluble receptor activators of nuclear factor-kappaB ligand and osteoprotegerin in bone metabolism of elderly women. Gerontology 55: 275 280

47. Boyce BF, Xing L (2008) Functions of RANKL/RANK/OPG in bone modeling and remodeling. Arch Biochem Biophys 473: 139-146.

48. Julian BA, Laskow DA, Dubovsky J, Dubovsky EV, Curtis JJ, et al. (1991) Rapid loss of vertebral mineral density after renal transplantation. $\mathrm{N}$ Engl Med 325: 544-550.

49. Sanchez CP, Salusky IB, Kuizon BD, Ramirez JA, Gales B, et al. (1998) Bone disease in children and adolescents undergoing successful renal transplantation. Kidney Int 53: 1358-1364

50. Kusec V, Smalcelj R, Puretic Z, Szekeres T (2004) Interleukin-6, transforming growth factor-beta 1 , and bone markers after kidney transplantation. Calcif Tissue Int 75: 1-6. 